\title{
Usos domas no gerenciamento da conversa: Foco, pressuposição e contrafactualidade
}

\author{
Uses of "mas" in the management of conversation: \\ Focus, presupposition and counterfactual
}

\begin{abstract}
Sandra Bernardo
Universidade do Estado do Rio de Janeiro - UERJ/Pontifícia Universidade Católica do Rio de Janeiro - Rio de Janeiro - Brasil
\end{abstract}

\section{Naira de Almeida Velozo}

Universidade do Estado do Rio de Janeiro - UERJ - Rio de Janeiro - Rio de Janeiro - Brasil

\begin{abstract}
Resumo:Análise de ocorrências do conectormas em uma sessão de mediação, etapa de um processo judicial, com vistas a testar hipóteses acerca das configurações de espaços mentais ativadas pelo uso do conector na conversa. Com base nos estudos acerca da linguagem como um Modelo Baseado no Uso (TOMASELLO, 2003a[1999]; FERRARI, 2011), naTeoria dos Espaços Mentais (FAUCONNIER, 1997) e no conceito de pressuposição, postula-se que o conectormas seja um construtor de espaços mentais que atua no gerenciamento discursivo cancelando implicaturas ou possibilitando a flutuação de pressuposições entre espaços; admite-se também que esse crie espaços contrafactuais; e ainda que seja responsável pelo deslocamento do foco de atenção entre os espaços de uma rede discursiva.
\end{abstract}

Palavras-chave:Mas. Espaços mentais. Foco.Pressuposição.Contrafactualidade.

Abstract: Occurrences' analysis of connector "mas" in a mediation session, a judicial process step, in order to test hypotheses about the settings of mental spaces activated by the use of the connector in the conversation. Based on the studies on language as a Usage-based Theory (TOMASELLO, 2003a [1999]; FERRARI, 2011), the Theory of Mental Spaces (FAUCONNIER, 1997) and the concept of presupposition, it is postulated that the "mas" connector is a builder of mental spaces that operates in the discursive management canceling implicatures or enabling assumption fluctuations between spaces; it is assumed that this also create counterfactual spaces; and is still responsible for the focus' attention shift between spaces of a discursive network.

Keywords: "Mas". Mental spaces. Focus. Presupposition. Counterfactual. 


\section{Introdução}

Neste estudo qualitativo, objetiva-se descrever as cinco primeiras ocorrências do conectormasem uma conversa mediada, visando a testar hipóteses para o desenvolvimento de uma proposta de descrição sociocognitiva desse conector. Para tanto, baseia-se, sobretudo, na perspectiva de linguagem como um Modelo Baseado no Uso (TOMASELLO, 2003a[1999]; FERRARI, 2011), naTeoria dos Espaços Mentais (FAUCONNIER, 1997) e no conceito de pressuposição.

As seguintes hipóteses serão investigadas: (i) acredita-se que o conectormas seja um construtor de espaços mentais que atua no gerenciamento discursivo cancelando implicaturas ou possibilitando a flutuação de pressuposições entre espaços mentais, como atestam os estudos de seu correspondente em inglês but (FAUCONNIER, 1997, p. 49); (ii) admite-se também que crie espaços contrafactuais; e ainda (iii) que seja responsável pelo deslocamento do primitivo semântico foco entre os espaços de uma rede conceptual.

Os dados analisados compõem a transcrição da primeira sessão de mediação de um processo da vara de família do Rio de Janeiro ${ }^{1}$. A mediação é uma forma alternativa de resolução de conflitos (ADR), praticada, com sucesso, em vários países. No Brasil, os processos de mediação foram possibilitados pela Lei $n^{\circ} 8.078$ de 11 de setembro de 1990 .

Acredita-se que a mediação supere o déficit de comunicação do sistema judiciário operacional e que, por isso, a partir das sessões mediadas, será possível obter acordos mais facilmente, já que o mediador é visto como o responsável por levar os mediandos a compreender que possuem visões diferentes sobre 0 problema a ser resolvido e que precisam respeitar o posicionamento um do outro para encontrarem uma solução satisfatória às duas partes.

\footnotetext{
${ }^{1} \mathrm{~A}$ transcrição elaborada a partir da gravação do caso integra o projeto de pesquisa "Contextos de intervenção de terceiras partes em situação de conflito" (projeto SHA - APQ 2129, FAPEMIG) do Prof. Dr. Paulo Cortes Gago. Nas convenções de transcrição adotadas, usam-se os símbolos desenvolvidos por Gail Jefferson, estabelecidos em Sacks, Schegloff e Jefferson (1974).
}

Além de avaliar as hipóteses acima, espera-se colaborar para uma reflexão acerca de como os sentidos são ativados e desativados durante a interação por meio de implícitos ou de pistas linguísticas, consideradas construções cognitivas subespecificadas cujos efeitos dependem da configuração do espaço pelo qual operam.

A fim de cumprir com os objetivos deste artigo, na primeira seção, retomam-se pressupostos teóricos acerca da linguagem num Modelo Baseado no Uso; na segunda, revisam-se postulados da Teoria dos Espaços Mentais relevantes para a análise deste artigo; na terceira, esclarece-se 0 conceito semântico-pragmático de pressuposição; na seção seguinte, apresenta-se a análise das ocorrências selecionadas; e, por fim, expõem-se algumas considerações que apontarão caminhos para o desenvolvimento de uma proposta de descrição sociocognitiva domas.

Neste estudo qualitativo, objetiva-se descrever as cinco primeiras ocorrências do conectormasem uma conversa mediada, visando a testar hipóteses para o desenvolvimento de uma proposta de descrição sociocognitiva desse conector. Para tanto, baseia-se, sobretudo, na perspectiva de linguagem como um Modelo Baseado no Uso (TOMASELLO, 2003a[1999]; FERRARI, 2011), naTeoria dos Espaços Mentais (FAUCONNIER, 1997) e no conceito de pressuposição.

As seguintes hipóteses serão investigadas: (i) acredita-se que o conectormas seja um construtor de espaços mentais que atua no gerenciamento discursivo cancelando implicaturas ou possibilitando a flutuação de pressuposições entre espaços mentais, como atestam os estudos de seu correspondente em inglês but (FAUCONNIER, 1997, p. 49); (ii) admite-se também que crie espaços contrafactuais; e ainda (iii) que seja responsável pelo deslocamento do primitivo semântico foco entre os espaços de uma rede conceptual.

Os dados analisados compõem a transcrição da primeira sessão de mediação de um processo da vara de família do Rio de Janeiro ${ }^{1}$. A mediação é uma forma alternativa de resolução de conflitos (ADR), 
praticada, com sucesso, em vários países. No Brasil, os processos de mediação foram possibilitados pela Lei no 8.078 de 11 de setembro de 1990 .

Acredita-se que a mediação supere o déficit de comunicação do sistema judiciário operacional e que, por isso, a partir das sessões mediadas, será possível obter acordos mais facilmente, já que o mediador é visto como o responsável por levar os mediandos a compreender que possuem visões diferentes sobre o problema a ser resolvido e que precisam respeitar o posicionamento um do outro para encontrarem uma solução satisfatória às duas partes.

Além de avaliar as hipóteses acima, espera-se colaborar para uma reflexão acerca de como os sentidos são ativados e desativados durante a interação por meio de implícitos ou de pistas linguísticas, consideradas construções cognitivas subespecificadas cujos efeitos dependem da configuração do espaço pelo qual operam.

A fim de cumprir com os objetivos deste artigo, na primeira seção, retomam-se pressupostos teóricos acerca da linguagem num Modelo Baseado no Uso; na segunda, revisam-se postulados da Teoria dos Espaços Mentais relevantes para a análise deste artigo; na terceira, esclarece-se o conceito semântico-pragmático de pressuposição; na seção seguinte, apresenta-se a análise das ocorrências selecionadas; e, por fim, expõem-se algumas considerações que apontarão caminhos para o desenvolvimento de uma proposta de descrição sociocognitiva domas.

\section{Linguagem: um modelo baseado no uso}

A Linguística Cognitiva (LC) advoga que se empregam habilidades cognitivas gerais, que também podem ser inatas, na aquisição da linguagem. Assim, não se nega que os seres humanos sejam programados biologicamente para adquirir uma língua, mas rejeita-se a hipótese de que há um sistema cognitivo inato e especializado que equipa o ser humano para o conhecimento linguístico.

Para defender a perspectiva da LC acerca da linguagem, retoma-se o estudo de
Tomasello(2003a[1999]), que considera a habilidade de se comunicar simbolicamente com indivíduos da mesma espécie uma adaptação biológica específica dos seres humanos; entretanto, rejeita a ideia de que há estruturas cognitivas inatas especializadas para a linguagem. Dessa forma, o Modelo Baseado no Uso proposto por Tomasello (2003a[1999]) enfatiza os processos de aprendizagem e atribui a aquisição da linguagem a duas habilidades cognitivas que não são especificamente linguísticas, mas relacionam-se também a outros domínios cognitivos. Tais habilidades cognitivas gerais são a identificação de padrões e a leitura de intenções.

Ferrari (2011, p.151) esclarece que "a identificação de padrões consiste na habilidade de reconhecer padrões e realizar análises estatísticas em sequências perceptuais, incluindo a cadeia sonora que constitui a linguagem". Assim, as crianças com menos de um ano procuram encontrar padrões repetidos naquilo que ouvem para construir unidades linguísticas. De acordo com Tomasello (2003b, apud Ferrari, 2011, p.151)2, a identificação de padrões envolve a habilidade de

- relacionar objetos e eventos similares, resultando na formação de categorias perceptuais e conceptuais para objetos e eventos;

- formar esquemas sensório-motores baseados na percepção recorrente de ações (reconhecimento de habilidades sensório-motoras básicas e reconhecimentos de ações como eventos, tais como engatinhar, andar, pegar um objeto, e assim por diante);

- realizar análise distribucional de sequências perceptuais e comportamentais (identificação e reconhecimento de combinações recorrentes de elementos em uma sequência, de modo a identificar e reconhecer sequências)

- criar analogias (reconhecimento de similaridades) entre duas ou mais totalidades (incluindo expressões linguísticas), com base na similaridade funcional de alguns elementos nessas totalidades.

\footnotetext{
${ }^{2}$ Os casos de citação indireta devem-se ao reconhecimento da qualidade da formulação de Ferrari (2011) em português sobre Linguística Cognitiva e não à ausência de leitura dos textos originais.
} 
Essas capacidades possibilitam que as crianças identifiquem padrões no modo como os adultos usam os símbolos linguísticos em diferentes contextos, e, dessa forma, construam as dimensões gramaticais (abstratas) da competência linguística humana. As crianças são capazes de identificar padrões não apenas em relação a aspectos formais da linguagem, como a capacidade de crianças prélinguísticas em reconhecer padrões silábicos de palavras em uma cadeia sonora, mas também em relação a aspectos funcionais (ligados ao significado).

Para aprender o uso convencional de uma palavra específica, por exemplo, a criança não só precisará reconhecer a mesma forma fonológica através de diferentes instâncias, como também terá necessidade de enxergar os padrões com que os adultos usam comunicativamente uma determinada forma, por meio de eventos de uso distintos. Como afirma Ferrari (2011), essa identificação funcional de padrões inclui desde a percepção de similaridade nos referentes distintos denominados por uma mesma palavra, como o termo bola, por exemplo, até a percepção de similaridades em diferentes relações indicadas pelos diversos usos de preposições, tais como para ou por.

Já a leitura de intenções trata-se da habilidade de perceber as outras pessoas como agentes mentais que podem ter crenças verdadeiras ou falsas acerca do mundo. Segundo Tomasello (2003b, apud Ferrari, 2011, p.153), as habilidades envolvidas na leitura de intenções consistem na habilidade de:

- compartilhar atenção com outras pessoas em relação a objetos e eventos de interesse mútuo;

- seguir a atenção e gestual de outras pessoas em relação a objetos distantes e eventos fora da interação imediata;

- dirigir ativamente a atenção dos outros para objetos distantes, através do ato de apontar, mostrar e usar outros gestos não linguísticos;

- aprender culturalmente (imitativamente) as ações intencionais dos outros, incluindo seus atos comunicativos resultantes de intenções comunicativas.
Todas essas habilidades definem a dimensão simbólica e funcional da comunicação linguística, que envolve a tentativa de manipular os estados mentais ou intencionais de outras pessoas. $\mathrm{Na}$ seção de análise, verificar-se-á que as diferentes funções domas relacionam-se às diversas leituras das intenções dos participantes da interação e à tentativa de manipular os estados mentais ou intencionais uns dos outros.

Em seguida, serão apontados alguns postulados da Teoria dos Espaços Mentais que se relacionam intrinsecamente à leitura de intenções e à manipulação de estados mentais.

\section{Teoria dos espaços mentais}

Espaços mentais são domínios cognitivos locais que refletem a divisão da informação à medida que o discurso se desenvolve. Segundo Ferrari (2011, p.109),

tais espaços são domínios conceptuais que contêm representações parciais de entidades e relações em um cenário percebido, imaginado ou lembrado. Assim, o espaço que ancora o discurso na situação comunicativa imediata (falante, ouvinte(s), lugar e momento da enunciação) é a BASE. A partir da BASE, outros espaços são normalmente criados para alocar informações que extrapolam o contexto imediato: falamos de passado e do futuro, de lugares distantes, de hipóteses, de arte e literatura e também de cenários que só existem em nossa imaginação.

Sendo assim, os espaços comportam elementos que podem ser projetados para novos espaços. Logo, cada novo espaço aberto herda a estrutura do espaço precedente. Ferrari (2009) observa que, no exemplo "No ano que vem, Maria vai viajar para Londres", o sintagma "no ano que vem" introduz um espaço temporal a partir do espaço base (B), considerado a âncora discursiva. Em B, tem-se o elemento "Maria", projetado no espaço temporal T. O espaço futuro $T$, simultaneamente, introduz um novo elemento, "Londres", e herda os elementos e a estrutura do espaço anterior. Dessa forma, em T, 
estabelece-se a relação de "viajar" entre a contraparte de "Maria", herdada de B, e o locativo "Londres".

Os domínios construídos dessa maneira são parcialmente ordenados por uma relação de subordinação. Um novo espaço M', por exemplo, é sempre construído em relação a um espaço existente $M$ que está em foco. Assim, $M$ é chamado de espaço paterno de M', e a relação de subordinação é representada por uma linha pontilhada, como se observa na Figura (1).

Figura 1 - Relação de subordinação entre espaços

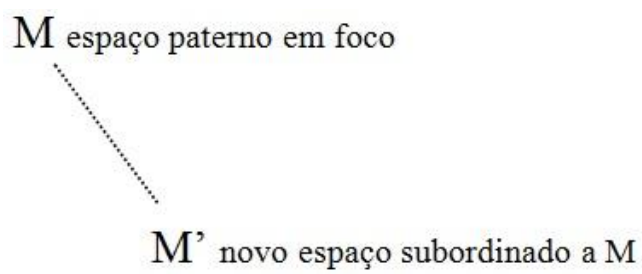

Fonte: autoras

Assim, os espaços construídos na conceptualização discursiva são organizados dentro de uma grade ordenada parcialmente. Em um determinado estágio do discurso, um dos espaços é a base para o processo cognitivo, e um dos espaços, possivelmente o mesmo, está em foco.

A construção do próximo estágio pode ser ativada em relação ao espaço base ou ao espaço foco. Portanto, os pontos de vista e os focos dos participantes do discurso mudam conforme a construção de novos espaços, mas, em qualquer etapa da construção da rede de espaços mentais, o espaço base permanece acessível, como um possível ponto de partida para outra construção.

Os espaços mentais são internamente estruturados por frames e modelos cognitivos e externamente ligados por conectores, que relacionam elementos e, mais comumente, estruturas através dos espaços. Além disso, novos elementos podem ser adicionados a um espaço por expressões linguísticas ou por condições pragmáticas.
Neste trabalho, dois dispositivos gramaticais são relevantes: os construtores de espaços mentais (spacebuilders) e os marcadores de pressuposição. Construtores de espaços mentais são expressões gramaticais que abrem um novo espaço ou mudam o foco de atenção de um espaço para outro. Dentre essas expressões, encontra-se o objeto de estudo deste artigo: mas sucedido pelos tipos de sentença que introduzem conector + cláusulas (proposições). Já os marcadores de pressuposição permitem que uma estrutura seja propagada para espaços próximos, criando contrapartes de elementos importantes para o encaminhamento do discurso.

O processo de construção dos espaços mentais envolve uma multiplicidade de funções (FAUCONNIER, 1997, p. 49):

a) construção de espaços e elementos que seguem um caminho dentro da rede de espaços mentais;

b) estruturação de espaçosinternamente;

c) ligação dos espaços externamente por meio de conectores;

d) indicação do espaço que está em foco e do tipo a que pertence (modo e tempo);

e) sinalização de estruturas que podem ser transferidas por omissão para espaços localizados mais acima na rede (a partir dos marcadores de pressuposição);

f) acesso a elementos e suas contrapartes (descrições definidas, nomes, anáforas);

g) introdução de papéis e ligação desses a valores;

h) estabelecimento de condições que permitirão o raciocínio dedutivo;

i) cancelamento de implicaturas por omissão (ativado por but, por exemplo).

Para que os participantes do discurso possam encontrar seu caminho através do labirinto de espaços mentais e usar o parcionamento das informações para desenhar inferências apropriadas, três noções dinâmicas são cruciais: base, espaço que funcionam como ponto de partida da construção da 
rede, para o qual é sempre possível retornar; ponto de vista, espaço a partir do qual outros são acessados e estruturados, ou construídos; e foco, espaço estruturado internamente no momento presente, sobre o qual a atenção é focalizada. É importante destacar que base, ponto de vista e foco não precisam ser distintos, frequentemente, não o são. Assim, pode-se observar o mesmo espaço atuando como ponto de vista e foco, ou base e foco,ou base e ponto de vista, outodos os três.

Para explicitar o processo de construção da rede de espaços mentais ao longo do discurso, e a atuação do conectormascomo um construtor desses espaços, retoma-se um exemplo de Fauconnier (1997, p. 44-51):

Achilles vê uma tartaruga. Ele a persegue. Ele acha que a tartaruga é lenta e que pode pegá-la. Mas ela é rápida. Se a tartaruga fosse lenta, Achilles a pegaria. Talvez a tartaruga seja, na verdade, uma lebre ${ }^{3}$.

O processo de construção cognitiva desse enunciado foi representado por Fauconnier (1997, p. 48), conforme a Figura (2).

Figura 2 - Conceptualização de Achilles e a tartaruga

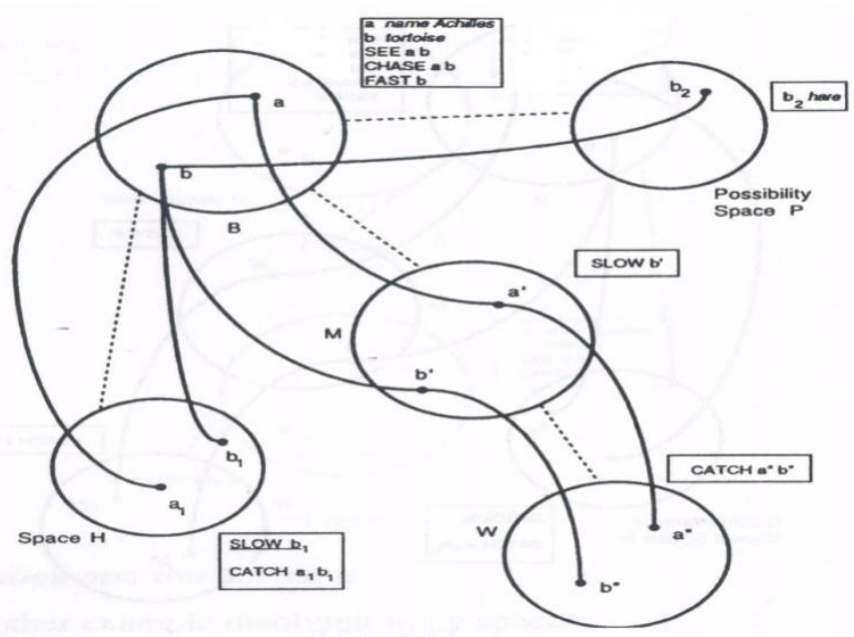

Fonte: Fauconnier (1997, p. 48)

\footnotetext{
${ }^{3}$ "Achilles sees a tortoise. He chases it. He thinks that the tortoise is slow and that he will catch it. But it is fast. If the tortoise had been slow, Achilles would have caught it. Maybe the tortoise is really a hare".
}

No exemplo, o espaço base corresponde à "realidade" da ficção e, no começo do discurso imaginário, é também o espaço do ponto de vista e do foco, uma vez que é o único espaço configurado até o surgimento da terceira sentença "Ele acha que a tartaruga é lenta e que ele pode pegá-la".

Por meio das pistas gramaticais da terceira sentença, o espaço de crença $M$ é construído e está necessariamente em foco. Nota-se que o foco deslocou-se do espaço base B para $M$, e que o espaço M é acessado a partir do ponto de vista do espaço B. Logo, observa-se uma subespecificação no processo: o espaço B é o ponto de vista, e o espaço $M$ é o foco no terceiro estágio. Isso é possível, em princípio, porque o ponto de vista pode permanecer em B ou mudar para o novo foco, o espaço $\mathrm{M}$.

$\mathrm{Na}$ próxima sentença, "Mas ela é rápida",a estrutura construída é incompatível com $\mathrm{M}$ e compreendida em relação a $B$, mostrando que a base, nesse caso, é mantida como ponto de vista e que o foco é deslocado para trás, para B; assim, a sentença leva os participantes envolvidos no discurso a retornarem ao espaço base.

O conectormas (but)é um indício pragmático que revela que a estrutura assumida implicitamente no espaço base [rápida b] - em que b corresponde à entidade tartaruga - difere daquela do espaço de crença [lenta b'], uma vez que a estrutura explícita construída pela cláusula introduzida pelo conector [rápida b"] é incompatível com sua contraparte [lenta $\left.b^{\prime}\right]$.

Com base na sentença "Se a tartaruga fosse lenta, Achilles poderia pegá-la.", configura-se o espaço contrafactual, que necessariamente se torna um foco. O ponto de vista permanece inalterado, na base, a partir da qual a construção do próximo espaço (espaço de possibilidade $\mathrm{P}$ ) será efetuada. Nessa fase, a configuração é igualmente compatível com o ponto de vista alterado [rápida b']; assim, o espaço hipotético é contrafactual [lenta b1] em relação à base [rápida b], e duas novas estruturas aparecem nele, H: lenta b1 pegar a1b1. Nesse caso, o modo condicional (se) é um sinal gramatical de que o espaço contrafactual está em foco. 
A alteração do ponto de vista é ativada devido à forma talvez da próxima sentença, pois o ponto de vista é ainda o da base quando o construtor de espaços talvez apresenta uma possibilidade no espaço $P$, no qual a contraparte de 'tartaruga' é 'lebre'. Essa contraparte b2, no novo espaço P, é acessada a partir da base por meio de uma descrição para seu gatilho b (tartaruga).

Verifica-se, portanto, que uma sentença de língua natural é cognitivamente complexa, porque incorpora informação e constrói instruções para todos esses níveis diferentes. Dessa forma, o tipo de significado que será produzido no momento depende da configuração do espaço mental, gerado pelo discurso anterior, ao qual a sentença atual se aplica. Logo, a Teoria dos Espaços Mentais compreende a sentença de uma língua natural como um conjunto subespecificado de instruções para a construção cognitiva de muitos níveis diferentes do processamento discursivo.

$\mathrm{Na}$ próxima seção, expõe-se o conceito de pressuposição assumido neste estudo.

\section{Pressuposição: uma noção semântico- pragmática}

Como no âmbito da Linguística Cognitiva, não se concebe uma separação entre semântica e pragmática, entende-se a pressuposição como uma relação semântico-pragmática, porque, numa abordagem experiencialista, busca-se lidar tanto com usos situados da língua quanto com certos tipos de efeitos intencionais.

Ilari e Geraldi (1994, p.76) afirmam que, "[e]m algum sentido (...), as pressuposições não fazem parte do conteúdo assertado". Assim, trata-se de um conhecimento compartilhado por falante e ouvinte, prévio à sentença proferida, ainda que seja desencadeado a partir dessa.

Frege (1892, apudCANÇADO, 2005, p. 33) observa que existe um tipo de conteúdo em certas sentenças que não é afetado quando essas são negadas ou postas em uma forma interrogativa, ou mesmo como uma condicional antecedendo outra sentença. Cançado (p. 33) exemplifica tal aspecto com as seguintes frases (1a-1a"').

(1-a) José emprestou o carro dele para Pedro.

(1-a') Não é verdade que José emprestou o carro dele para Pedro.

(1-a") José emprestou o carro dele para Pedro?

(1-a"') Se José emprestou o carro dele para Pedro, Pedro deve estar contente.

Nessas sentenças, o fato de o carro pertencer a José permanece inalterado. Pode-se afirmar, portanto, que as orações afirmativa, negativa, interrogativa e condicional, ditas família de uma sentença, compartilham um tipo específico de conteúdo. A esse conteúdo compartilhado Frege deu - nome de pressuposição. Dessa forma, as sentenças acima pressupõem a sentença o carro pertence a José.

No âmbito da teoria dos espaços mentais, os elementos evocados pelo contexto prévio da conversação ou considerados familiares aos participantes da/na interação são ativados pressuposicionalmente e podem se propagar pelos espaços mentais. Assim, numa perspectiva sociocognitiva, a pressuposição extrapola o sentido das palavras usadas na construção de sentido, como se observará na próxima seção, dedicada à análise.

\section{Conector mas: um construtor de espaços multifuncional}

Escolheu-se analisar as cinco primeiras ocorrências do conectormas na primeira sessão de um caso de mediação desenvolvido em paralelo a um processo de regulamentação de visitas. Tal sessão ocorreu no dia 29 de maio de 2007, na Vara de Família do Fórum de uma cidade do interior do estado do Rio de Janeiro. No processo, contemplava-se a possibilidade de o pai, o requerente, encontrar-se com os filhos, Vitor e Íris, com mais frequência, não apenas a cada quinze dias, durante os finais de semana, conforme fora estabelecido. A gravação dessa sessão totalizou 45 minutos de conversa, os quais foram transcritos de acordo com 0 
procedimento da Análise da Conversa Etnometodológica (AC).

$\mathrm{Na}$ entrevista de mediação, utilizam-se pseudônimos para identificar os participantes. Em vista disso, verifica-se a seguinte distribuição: Sônia, assistente social, é a mediadora das sessões; Amir é o requerente do processo de pedido de regulamentação de visita; Flávia é a requerida; e Vitor e Íris são filhos de Amir e Flávia, os quais são divorciados. A análise partirá da transcrição dos excertos.

\section{Excerto 1}

Sônia: nem me lembro mais que é o requerente desse processo, quem é que começou, mas é que veio pedir ao juiz, botou a VIDA pro juiz pro juiz decidir.

Para explicitar o parcionamento das informações desse excerto e a função cumprida pelomasno trecho, propõe-se o diagrama da Figura (3) $)^{4}$

Figura 3 - Parcionamento das informações do excerto 1

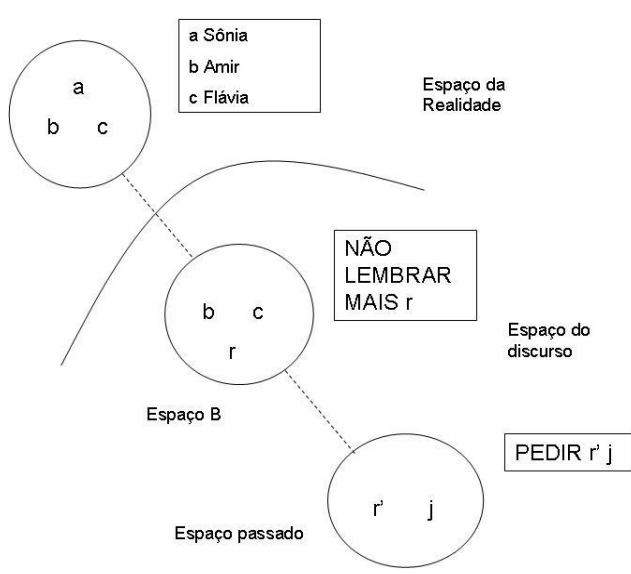

Fonte: autoras

No diagrama, a linha curva separa o espaço de realidade do espaço do discurso. No espaço de realidade da mediação, observam-se três entidades: Sônia (a), mediadora, e Amir (b) e Flávia (c),

${ }^{4}$ Optou-se por não desenhar a linhas que ligariam as contrapartes dos elementos evocados pelos espaços abertos, visto que as relações entre essas contrapartes podem ser capturadas pelas repetições das letras. mediandos. Já no espaço do discurso, notam-se dois espaços, um epistêmico, que diz respeito aos pensamentos da mediadora, e outro que apresenta um evento passado.

O primeiro espaço do discurso é construído a partir de uma expressão desencadeadora de pressuposição - nem me lembro mais -, que nega um espaço implícito em que Sônia sabia quem era o requerente do processo. Como esse espaço é o ponto de partida desse trecho discursivo, é chamado espaço base (B), em que Amir (b) e Flávia (c) são apontados como possíveis valores para o papel "requerente". Nesse estágio de construção do discurso, o espaço base é também aquele segundo o qual o ponto de vista é formado e o espaço em foco.

Ao utilizar o conectormas, a mediadora introduz uma cláusula que constrói um espaço de evento passado em que o requerente atribui ao juiz a responsabilidade de decidir um aspecto da vida da família - por quanto tempo o pai pode ficar com os filhos. Esse segundo espaço discursivo herda a entidade "requerente", agora representada por r', e apresenta uma nova entidade, o "juiz" (j).

Nota-se que o ponto de vista sobre o caso permanece no espaço base - saber quem é o requerente não é importante -, porém o foco de atenção é deslocado do espaço base para o espaço de evento. Assim, a importância recai sobre o fato de as partes, em um primeiro momento, terem permitido que o juiz decidisse sobre suas vidas, em vez de os próprios envolvidos entrarem em um acordo sobre o tempo que passam com os filhos nas sessões de mediação.

Dessa forma, o conector atua como um focalizador, que desvia o foco de atenção do requerente do processo para o fato de as partes atribuírem ao juiz uma decisão que elas próprias podem tomar, ou seja, desvia o foco de atenção do espaço base para o espaço de evento. Ao negar a importância do requerente, a mediadora reforça sua intenção de levar os mediandos a um acordo.

\section{Excerto 2}


Sônia: MESmo assim, é MUlto mais interessante que os próprios envolvidos decidam sobre a SUA vida, SUAS vidas, né.

Flávia: mais as crianças, né.

Sônia: no caso aqui muito mais as vidas das crianças. mas que não há como negar que atinge diretamente a vida de cada um

Na passagem (2), o conector atua novamente como um focalizador, como se observa na Figura (4), na qual apenas a construção cognitiva do último turno de fala é representada.

Figura 4 - Conceptualização demasfocalizador

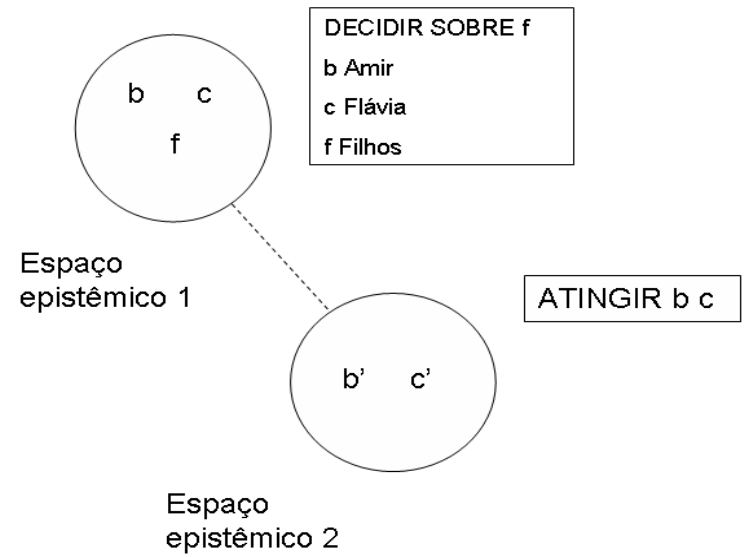

Fonte: autoras

Na primeira cláusula da coordenação, Sônia concorda com o ponto de vista de Flávia - é muito mais interessante que as partes possam decidir sobre as vidas de seus filhos, em vez de delegarem essa função ao juiz -, contudo, na segunda cláusula, a mediadora reafirma a importância dos encontros de mediação, para que as partes decidam sobre suas próprias vidas, o que já havia sido ressaltado no primeiro turno de fala do excerto (1)

Nota-se que o conector desvia o foco de atenção do primeiro espaço de crença para o segundo e, portanto, da entidade "filhos", ou "crianças", para os mediandos. Os espaços encontram-se na realidade do evento discursivo em andamento - a mediação.

Excerto 3

Flávia: Essa semana ele tá tranquilo porque esse fim de semana ele ficou comigo. mas ele te- vem de lá com medo, e fala que o pai fica na cama chorando.
No trecho (3), o conectormas constrói um espaço contrafactual em relação à base, conforme a Figura (5).

$\begin{array}{llll}\text { Figura } & 5 & - & \text { Conceptualização }\end{array}$ demascontrafactualizador

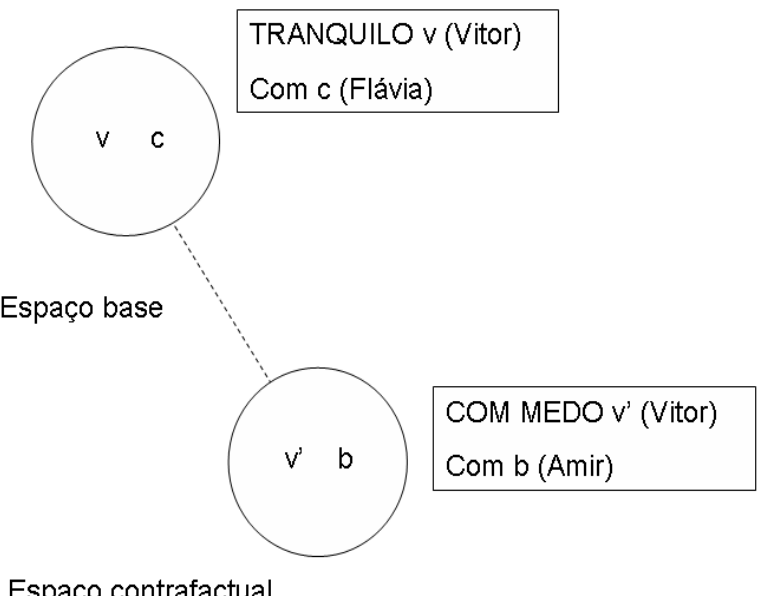

Fonte: autoras

A primeira cláusula coordenada pelo conectormasativa um espaço que funciona como ponto de partida para a construção dessa etapa do discurso; logo, como o espaço base. Nesse momento da conceptualização discursiva, o ponto de vista de que ficar com a mãe faz bem a Vitor está na base, assim como o foco de atenção.

O conectormas, no entanto, cria um novo espaço que passa a ser o foco, referente ao evento passado em que Vitor esteve com o pai. Esse novo espaço foco acrescenta informação ao ponto de vista da base, que pode ser explicitado como ficar com a mãe faz bem a Vitor e ficar com o pai faz mal. Assim, o novo espaço criado pelo uso do conector gera uma contrafactualidade em relação à entidade v (Vitor), à qual, no primeiro espaço, é atribuída a característica de ser tranquilo e, no segundo, de ter medo. A contrafactualidade, nesse caso, é importante argumentativamente, pois funciona como um argumento a mais para a tese de Flávia de que o pai não deve passar mais tempo com os filhos.

Excerto 4 
Flávia: =e isso não afeta. uma criança estando junto. o psicológico do meu filho como é que fica.

Sônia: provavelmente sim. mas esse é o pai do vitor.

Nesse excerto, verifica-se que o conectormasatua no cancelamento de implicaturas. A Figura (6) representa a relação entre os espaços de conceptualização do excerto (4).

Figura 6 - Conceptualização demasno cancelamento de implicatura

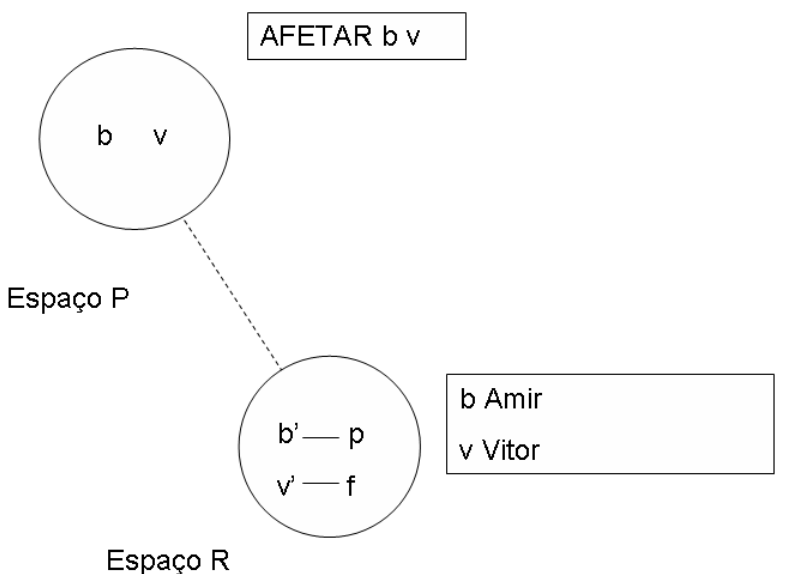

Fonte: autoras

A primeira cláusula da fala de Sônia ativa um espaço de possibilidade $(P)$ devido à utilização do advérbio provavelmente. O ponto de vista expresso nesse espaço é compatível com a pressuposição gerada pela pergunta de Flávia de que o estado psicológico do ex-marido, que, no momento do discurso, encontrava-se com depressão e síndrome do pânico, afetaria o filho Vitor. Isso levaria a medianda a crer que Sônia concordaria com sua tese de que Amir não deve passar mais tempo com o filho; no entanto, a mediadora quebra essa expectativa com a cláusula introduzida pelo conectormas.

O novo espaço, subespecificado por conector seguido de cláusula, passa a ser o espaço foco, em que a paternidade de Amir é enfatizada como um argumento biológico que corrobora um ponto de vista contrário ao do espaço base, a saber: Amir deve passar mais tempo com o filho. No diagrama, nota-se que a paternidade de Amir é representada por um traço, característico de uma relação de identidade, que une os valores b' (Amir) e v' (Vitor), herdados do espaço base $(P)$, aos seus papéis $p$ (pai) e $f$ (filho), respectivamente, por meio de uma projeção papelvalor. Logo, nesse trecho, o conector altera o foco de atenção e cancela a implicatura feita por Flávia.

\section{Excerto 5}

Flávia: é. inclusive você falou na última visita que é o pai que a gente escolheu, não é, que a gente escolheu pra si. Mas ele não é quem eu escolhi, porque ele é outra pessoa, atualmente ele é outra pessoa. quem eu escolhi era completamente diferente, era uma pessoa generosa, mu::ito melhor do que agora. não era mentirosa, não armava situações contra mim, entendeu.

Nesse trecho, o conector atua novamente como um construtor de espaço contrafactual, conforme se verifica na Figura (7).

$\begin{array}{llll}\text { Figura } & 7 & - & \text { Conceptualização }\end{array}$ demascontrafactualizador
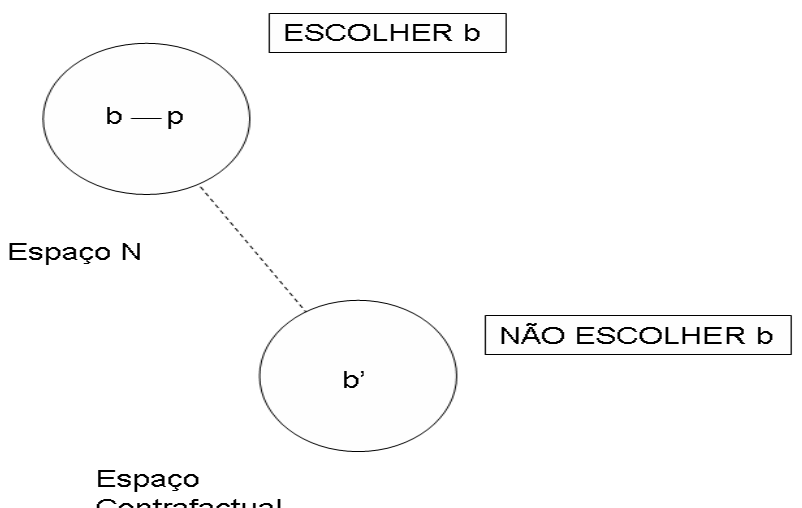

Fonte: autoras

A primeira cláusula coordenada ativa um espaço de narração em que o discurso proferido por Sônia em um encontro anterior é retomado. No discurso relatado, o ponto de vista de Flávia é mesclado ao de Sônia, e Amir é apontado como o pai escolhido para os filhos da medianda, o que é representado no diagrama pela relação papelvalor, identificada pelo traço que une a entidade $b$ (Amir) à sua contraparte $\mathrm{p}$ (pai) no espaço $\mathrm{N}$.

Com a cláusula introduzida pelomas, Flávia nega que Amir seja a mesma pessoa escolhida por ela, uma vez que não possui mais as mesmas características. Assim, o foco e o ponto de vista 
são transferidos para o novo espaço, que é contrafactual à base, uma vez que a contraparte b' (Amir com novas características) não é compatível à b (Amir com características de pai).

Nesse trecho, o espaço mental aberto por meio domas enfatiza a desqualificação de Amir como pai. Assim como nos demais analisados, percebe-se o papel domas na conceptualização argumentativa, já que é utilizado como um construtor de espaço mental para negociação de posições contrárias no andamento discursivo, preparando os interlocutores para uma réplica.

\section{Considerações finais}

As breves análises deste artigo confirmam as hipóteses iniciais, a saber: o conectormas funciona como um construtor de espaços mentais que atua no gerenciamento discursivo cancelando implicaturas ou possibilitando a flutuação de pressuposições entre espaços; também é um construtor de espaços contrafactuais; e ainda é responsável pelo deslocamento do primitivo semântico foco entre os espaços de uma rede.

Acredita-se que haja uma relação direta entre os tipos de espaços mentais configurados a partir do uso desse conector e os esquemas imagéticos que fundamentam tais usos na interação, ou seja, pretende-se verificar se o mesmo tipo de espaço é construído a partir de uma base cognitiva estável comum. Assim, a corroboração dessas hipóteses, que apontam diferentes funções domasno gerenciamento da conversa, possibilitarão o desenvolvimento de uma proposta de descrição sociocognitiva desseconector como uma categoria radial.

Observou-se ainda que o mas funciona como um gatilho que atua na construção, reconstrução e desconstrução de pressupostos, orientando, assim, os propósitos argumentativos da conversa, ao sinalizar intenções e posições dos participantes da interação.

\section{Referências}

ALMEIDA, Maria Lucia L. et al (Org.). Linguística Cognitiva em foco: morfologia e semântica. Rio de Janeiro: Publit, 2010.

BERNARDO, Sandra Pereira. Foco e ponto de vista na conversa informal: uma abordagem sóciocognitiva. 2002. 221f. Tese (Doutorado em Linguística) - Faculdade de Letras, Universidade Federal do Rio de Janeiro, Rio de Janeiro, 2002.

CANÇADO, M.Manual de Semântica: noções básicas e exercícios. 1. ed. Belo Horizonte: Editora UFMG, 2005.

DURANTI, Alessandro. Trocas Conversacionais. Tradução de Letícia Loder (mimeo). In: Duranti, Alessandro. Linguistic anthropology. Cambridge: Cambridge University Press, 1997.

FAUCONNIER, Gilles. Mappings in thought and language. Cambridge: Cambridge University Press, 1997.

FERRARI, L. V. Espaços Mentais e Construções Gramaticais: do uso linguístico à tecnologia. 1. ed. Rio de Janeiro: Imprinta, 2009.

Introdução à Linguística Cognitiva. São Paulo: Contexto, 2011.

FERRARI, L. e SWEETSER, E. Subjectivity and upwards projection in mental space structure. In: Viewpoint in language; a multimodal perspective. Cambridge: Cambridge University Press, 2012. p.4768.

GAGO, Paulo Cortes. A organização sequencial da conversa. Calidoscópio, v.3, n.2, p.61-73, maio/ago.o de 2005.

GARCEZ, Pedro M. Transcrição como teoria: a identificação dos falantes como atividade analítica plena. In: Moita Lopes, L. P.; Bastos, L. C. (Orgs.). Identidades: recortes multi e interdisciplinares. São Paulo: Mercado das Letras, 2002.

ILARI, Rodolfo; GERALDI, João Wanderley. Semântica. São Paulo: Ática, 1994.

SACKS, H.; SCHEGLOFF, E.; JEFFERSON, G. Sistemática elementar para a organização da tomada de turnos para a conversa. Language, v. 50, n. 4, 1974, p.696-735.

SAMPAIO, Lia Regina Costaldi; BRAGA NETO, Adolfo. $O$ que é mediação de conflitos. São Paulo: Brasiliense, 2007. (Coleção primeiros passos; 325).

TOMASELLO, Michael. Origens Culturais da Aquisição do Conhecimento Humano. São Paulo: Martins Fontes, 2003a[1999].

Constructing a language: a usage-based theory of language acquisition. Cambridge: Harvard University Press, 2003b. 
VELOZO, Naira A.Os esquemas de FORÇA e a metáfora da GUERRA: uma análise sociocognitiva dos usos do mas em mediação. Dissertação (Mestrado em Linguística) - Instituto de Letras, Universidade do Estado do Rio de Janeiro. Rio de Janeiro, 2012.

Signo [ISSN 1982-2014]. Santa Cruz do Sul, v. 40, n. 67, p.89-100, jan./jun. 2015. 